\title{
Ethanol Sensing Properties of F Doped ZnO Thin Films by Spray Pyrolysis
}

\author{
E. U. Masumdar ${ }^{\mathrm{a}}$ \\ a Thin Film Physics Laboratory, \\ Department of Physics, Rajarshi Shahu \\ Mahavidyalaya - Latur-413512, Maharashtra, India.
}

\author{
M. A. Barote ${ }^{b *}$ \\ B Department of Physics, Azad College, \\ Ausa-413520, Maharashtra, \\ India. $(*$ Corr. Author)
}

\begin{abstract}
The F doped $\mathrm{ZnO}$ thin films were deposited on preheated amorphous glass substrates using spray pyrolysis technique. Among all the deposited thin films, the 4 at\% $\mathrm{F}$ doped $\mathrm{ZnO}$ film shows the maximum response $(\sim 20.5 \%)$ at $300{ }^{\circ} \mathrm{C}$ to $1000 \mathrm{ppm}$ of Ethanol in air. The response time of $145 \mathrm{~s}$ and corresponding recovery time is $155 \mathrm{~s}$ is observed for 4\% F doped ZnO thin film.
\end{abstract}

Keywords: ZnO thin films, recovery time, response time

\section{INTRODUCTION}

Doped $\mathrm{ZnO}$ films offer a promising alternative to indium tin oxide (ITO) as a transparent conducting front contact layer in $\mathrm{CdTe} / \mathrm{CdS}$ solar cells. The substitutional doping of $\mathrm{ZnO}$ films with group III metals such as Al, B and $\mathrm{Ga}$ has been widely reported [1-5], however outdiffusion of the electrically active metal dopants during subsequent cell fabrication procedures can lead to detrimental effects on device performance. It has been shown, using reactive $\mathrm{RF}$ sputtering, that $\mathrm{ZnO}$ films can instead be doped with fluorine and maintain comparable electrical and optical properties to those of the group III doped films [6-9]. Such films should be better suited for maintaining stability in $\mathrm{CdTe} / \mathrm{CdS}$ solar cells where the diffusion of $\mathrm{F}$ out of the layer during subsequent high temperature fabrication of $\mathrm{CdS}$ and CdTe layers is unlikely to cause a significant degradation in device performance [10-12]. Apart from the academic interest, the fluorine doping has several potential advantages over the wellknown and successful In-doping, such as low cost and abundance. More over fluorine does not introduce significant perturbation into the conduction band, due to the size compatibility of the oxygen and fluorine atoms [13-14]. Fluorine was expected to occupy the oxygen site in $\mathrm{ZnO}$ and hence promoting the conductivity of the film [15].

\section{EXPERIMENTAL DETAILS}

The F-doped $\mathrm{ZnO}$ films were deposited onto amorphous glass substrates, chemically cleaned, using spray pyrolysis method at $450{ }^{0} \mathrm{C}$ substrate temperature. $0.5 \mathrm{M}$ solution of zinc acetate dehydrate $\left[\mathrm{Zn}\left(\mathrm{CH}_{3} \mathrm{COO}\right)_{2} .2 \mathrm{H}_{2} \mathrm{O}\right]$ diluted in methanol and deionized water (3:1) was used for all the films, and ammonium fluoride $\left(\mathrm{FNH}_{4}\right)$ was added to starting solution for fluorinedoping. Zinc acetate dehydrated and ammonium fluoride solutions were mixed together in different volume proportions ranging from 1 at $\%$ to 5 at $\%$ in steps of $1 \%$. Air was used as the carrier gas, pressure at 0.2 bar. The ultrasonic nozzle to substrate distance was $28 \mathrm{~cm}$ and during deposition, solution flow rate was held constant at 3 $\mathrm{ml} / \mathrm{min}$.

\section{RESULTS AND DISCUSSIONS}

\section{(a) Effect of temperature and Ethanol concentration}

Fig. 1 represents the sensing characteristics of the F-doped $\mathrm{ZnO}$ films as a function of the operating temperature for $1000 \mathrm{ppm}$ concentrations of Ethanol in air. It is observed that $\mathrm{F}$ dopant enhances the response of the films to Ethanol. Among all the films, the 4 at $\%$ F-doped $\mathrm{ZnO}$ film shows the maximum response $(\sim 20.5 \%)$ at 300 ${ }^{\circ} \mathrm{C}$ to 1000 ppm of Ethanol in air.

Fig. 2 represents the sensing characteristics of the $\mathrm{F}$ doped $\mathrm{ZnO}$ film as a function of Ethanol concentration in air at different $\mathrm{F}$ at\%. It is observed in the figure that $\mathrm{F}$ concentration increased, the response increases rapidly in the lower concentration region of Ethanol, while it increases gradually at higher concentrations of Ethanol. For a low concentration $(250 \mathrm{ppm})$, there is a smaller surface coverage of Ethanol molecules on the film and hence the surface reaction proceeds slowly. On an increase in gas concentration to $1000 \mathrm{ppm}$ the surface reaction increases due to a larger surface coverage of Ethanol molecules, resulting in a rapid increase in response. On a further increase in gas concentration to $1250 \mathrm{ppm}$, the surface coverage of Ethanol molecules on the film begins to decrease which leads to a gradual decrease in response. 


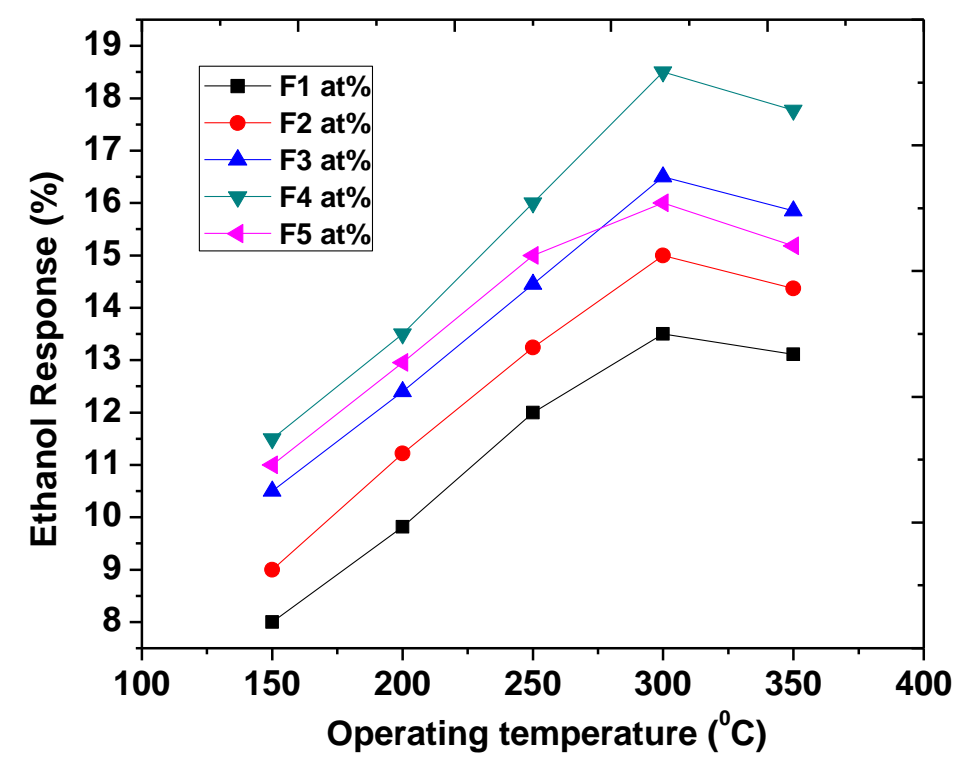

Figure 1: The variation of Ethanol response of $\mathrm{F}: \mathrm{ZnO}$ film for different $\mathrm{F}$ at $\%$ to $1000 \mathrm{ppm}$ Ethanol at different temperatures

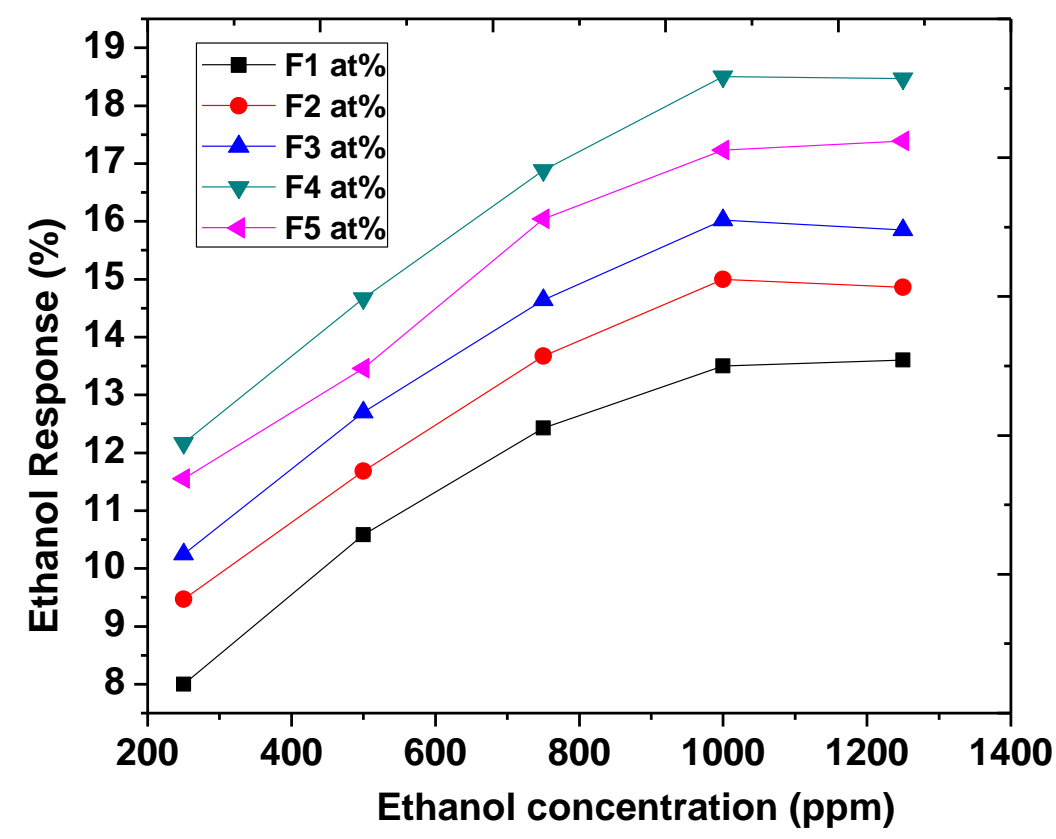

Figure 2: The variation of Ethanol response of F: $\mathrm{ZnO}$ film to different Ethanol concentrations

(b) Dynamic gas response transients of $\mathrm{F}: \mathrm{ZnO}$ film to Ethanol

Fig. 3 represents the transient response characteristics of the $\mathrm{F}$ doped $\mathrm{ZnO}$ films to $1000 \mathrm{ppm}$ of Ethanol vapor in air at $300{ }^{\circ} \mathrm{C}$. It is found that in case of the 4 at\% F-doped film, the response time to attain the maximum response value is almost the same $(\sim 20.5 \%)$ as that of the $1 \% \mathrm{~F}$ doped $\mathrm{ZnO}$ film. But in other F-doped films, the corresponding recovery time increases. On the other hand, the response time of the doped films is observed to decrease with an increase in F-dopant concentration. 


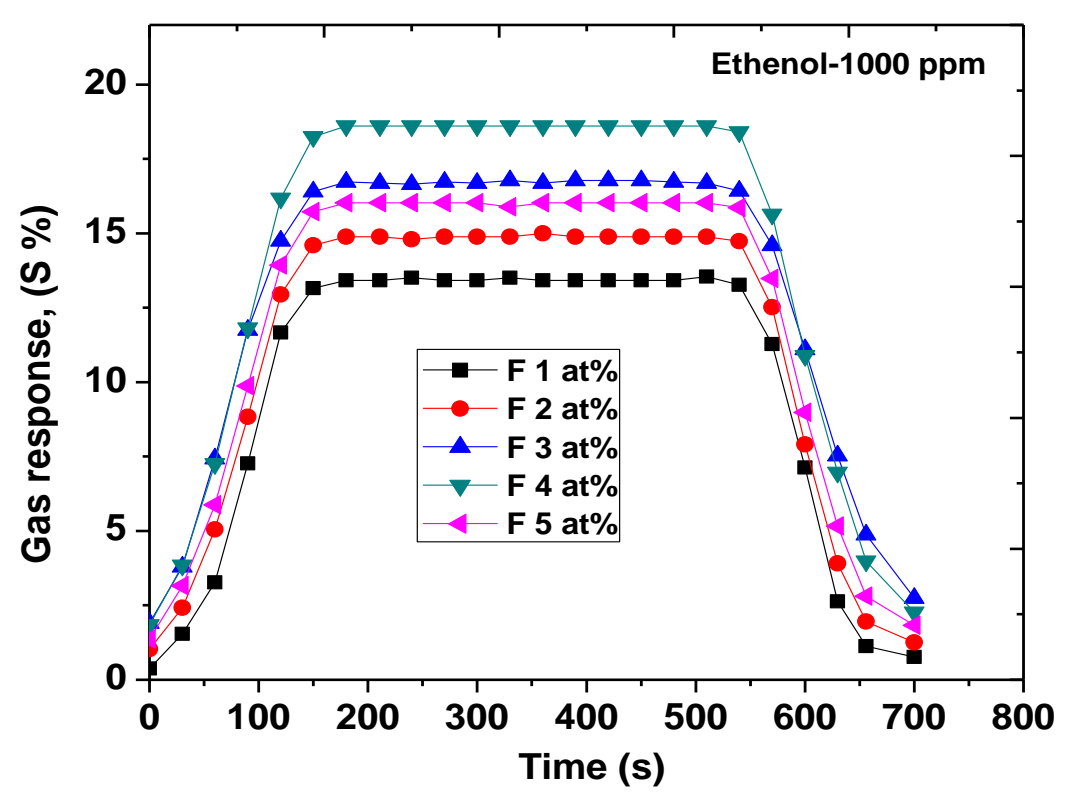

Figure 3: Dynamic Ethanol transient response of $\mathrm{ZnO}$ films for different $\mathrm{F}$ at $\%$ exposed to $1000 \mathrm{ppm}$ Ethanol at an operating temperature of $573 \mathrm{~K}$.

\section{(c) Response and recovery time periods for Ethanol}

From the Fig. 4, the response time of $145 \mathrm{~s}$ and corresponding recovery time is $155 \mathrm{~s}$ is observed for $4 \% \mathrm{~F}$ doped $\mathrm{ZnO}$ thin film. from the Figure it is found that as $\mathrm{F}$ concentration increases in $\mathrm{ZnO}$ lattice response and recovery time decreases up to 4 at $\%$ and further increase in $\mathrm{F}$ concentration to 5 at $\%$ both response and recovery time increased.

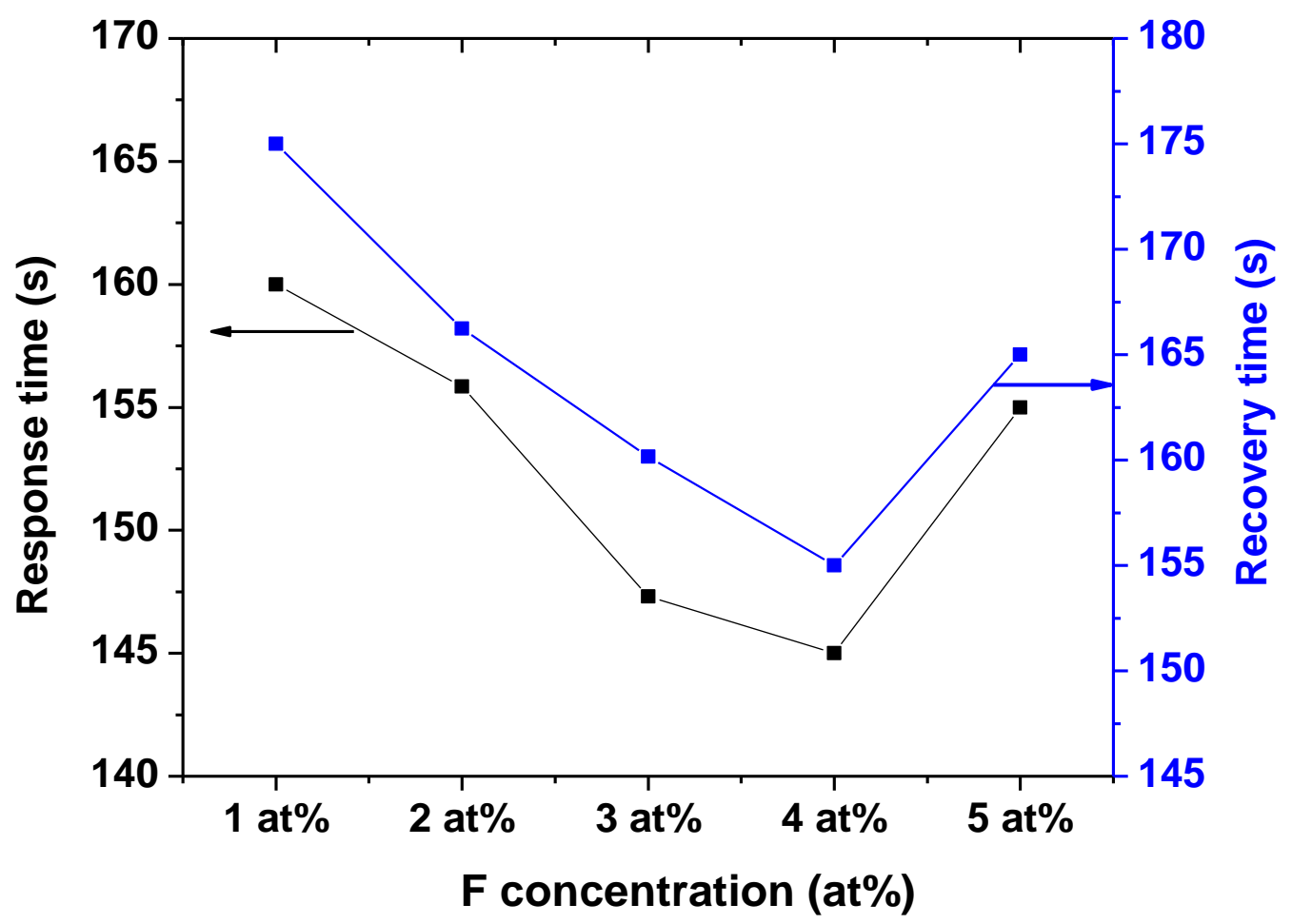

Figure 4: The variation of response and recovery time periods of $\mathrm{ZnO}$ films for different $\mathrm{F}$ at $\%$ upon exposure of $1000 \mathrm{ppm}$ Ethanol. 


\section{CONCLUSION}

The $\mathrm{ZnO}$ and $\mathrm{F}$ doped $\mathrm{ZnO}$ thin films were deposited by simple spray pyrolysis technique. As we increase the gas concentration to $1000 \mathrm{ppm}$ the surface reaction increases due to a larger surface coverage of Ethanol molecules, resulting in a rapid increase in response. On a further increase in gas concentration to $1250 \mathrm{ppm}$, the surface coverage of Ethanol molecules on the film begins to decrease which leads to a gradual decrease in response. The response time of $145 \mathrm{~s}$ and corresponding recovery time is $155 \mathrm{~s}$ is observed for $4 \% \mathrm{~F}$ doped $\mathrm{ZnO}$ thin film.

\section{REFERENCES}

[1] S. Fay, J. Steinhauser, N. Oliveira, E. Vallat-Sauvain, C. Ballif, Thin Solid Films 515 (2007) 8558.

[2] T. Minami, T. Miyata, Y. Ohtani, Y. Mochizuki, Jpn. J. Appl. Phys. 45 (2006) 409.
[3] C. Agashe, O. Kluth, J. Hupkes, U. Zastrow, B. Rech, M. Wuttig, J. Appl. Phys. 95 (2004) 1911.

[4] R.E. Treharne, K. Durose, Thin Solid Films (2010), doi:10.1016/j.tsf.2010.12.126.

[5] Y. Tsai, N. Wang, C. Tsai, Mater. Lett. (2009) 1621.

[6] D. Ku, Y. Kim, K. Lee, T. Lee, B. Cheong, T. Seong, W. Kim, J. Electroceram. 23 (2009) 415.

[7] R.E. Treharne, K. Durose, Thin Solid Films 520 (2011) 13131317.

[8] A. Guillen-Santiago, M de la L. Olvera, A. Maldonado, R. Asomoza and D. R. Acosta, Phys. Stat (a), Sol. 201, (2004) 952.

[9] Ratheesh Kumar P. M., Ph. D. thesis, Cochin University of Science and Technology Cochin, January 2007

[10] A. El Hichou, A. Bougrine, J. L. Bubendorff, J. Ebothe, M. Addou and M. Troyon, Semicond. Sci. Technol. 17, (2002) 607.

[11] J. Rodriguez-Baez, A. Maldonado, G. Torres-Delgado, R. Castanedo-Perez, M. de la, L. Olvera, Mater. Lett. 60 (2006) 1594.

[12] J.H. Lee, B.W. Yeo, B.O. Park, Thin Solid Films 457 (2004) 333.

[13] K. Ellmer, J. Phys. D Appl. Phys. 34 (2001) 3097.

[14] H.J. Ko, Y.F. Chen, S.K. Hong, H. Wenisch, T. Yao, Appl. Phys. Lett. 77 (2000) 3761.

[15] R.G. Gordon, MRS Bull. 25 (2000) 52. 